\title{
Enhancing off-site manufacturing through early contractor involvement (ECI) in New Zealand
}

David Finnie MConst (Construction Law), BConst (QS), GCTLT, Dip QS, MNZIQS, MNZIOB, LBP (Site 2 \& Carp)

Senior Lecturer in Quantity Surveying, College of Engineering, Construction and Living Sciences, Otago Polytechnic, Dunedin, New Zealand

(corresponding author: david.finnie@op.ac.nz)
Naseem Ameer Ali PhD Civil Engr, MSc Const Law \& Arb, MSC Arch, BSC (Hons), CDipAF, Cert Adj (RICS), Cert Adj (KLRCA), PPRISM, FRISM, FCIOB, FCIArb, MNZIQS, MRICS, MAPM, AIQS (Affil), Reg QS (NZ), Reg QS (M'sia)

Senior Lecturer in Quantity Surveying, School of Engineering and Advanced Technology, Massey University, Auckland, New Zealand

Kenneth Park PhD, MSc, BSC, FHEA, MCIOB, MRICS, CCM, PMP

Senior Lecturer in Construction, School of Enginieering \&

Applied Science, Aston University, Birmingham, UK

(Orcid:0000-0002-8406-3847)

\begin{abstract}
Procurement strategies that enable early contractor involvement (ECI) in design may enhance off-site manufacturing (OSM) by overcoming previously identified barriers to its uptake. Involving constructors during the design stage can reduce the risk of design buildability issues, and standardising traditionally bespoke ECl processes may help overcome cultural resistance to unfamiliar OSM technology. Following literature review and using case studies, document analysis and legal doctrine, a two-stage ECI conceptual process model for New Zealand is proposed. This was tested and refined following feedback at a conference. The model comprises a first-stage pre-construction contract and a second-stage standard-form construction contract. Key process variables are considered with solutions to provide collaboration and transparency while maintaining competitive fixed pricing across the supply chain. Legal doctrine analysis is used to distinguish between design buildability obligations and design codes compliance. The model contributes towards the development of a standard form for pre-construction contracts.
\end{abstract}

\section{Introduction}

\subsection{Early contractor involvement}

Integrating design and production has been a principle of lean design and construction inspired by the Toyota production system, which focuses on eliminating non-value-adding activities and waste through the whole production system in the supply chain. Jorgensen and Emmitt's (2007) ethnographic case studies identified crucial factors influencing effective lean integration. These include identifying client values, project team and planning process, transparent decision-making, management and leadership, continuous learning and establishing an appropriate project delivery framework. In particular, an appropriate delivery framework is fundamental as it affects other factors such as incentives, resources (including time, financial means and human and organisational resources) and contracts in order to integrate design and construction as an overall lean approach. Similarly, this aligns with definitions of construction procurement decisions being the process of acquiring the resources required to realise a construction project (see the Australia and New Zealand Government Procurement Agreement (Australia and New Zealand Governments, 2013)). In addition, Toolanen (2008) included the choice of an appropriate governance structure, allocation of contractual obligations and form of compensation.

The seventh edition of Civil Engineering Procedure (ICE, 2016: p. 161) suggests that early-contractor involvement (ECI) denotes '... a non-traditional procurement route, where a contractor's skills are introduced early into a project to bring design 'buildability' and cost efficiencies to the pre-construction phase'.
The term 'ECI' may be used as a concept to describe any procurement strategy that involves the contractor during the design phase, such as design and build (DB), management contracting $(\mathrm{MC})$ or construction management $(\mathrm{CM})$, or as its own procurement system, typically referred to as a two-stage procurement process, such as the 'conditional' pre-construction contract promoted by Mosey (2011). This may be contrasted with the traditional single-stage tender model, where contractors are invited to bid after designs are fully developed.

\subsection{Construction and off-site manufacturing in New Zealand}

The New Zealand (NZ) construction industry generates over NZ\$30 billion ( $£ 15.7$ billion) per annum (MBIE, 2013). It contributed over $6 \cdot 3 \%$ of the GDP in 2010 growing from $5 \%$ in 2008. Being a significant industry in NZ, even a $1 \%$ saving in process efficiency could equate to a saving of up to NZ\$300 million ( $£ 157$ million) per year, potentially without affecting the quality or delivery of the built asset. Despite this growth, there are considerable labour shortages, poor productivity issues and lack of effective project delivery. Similar to these issues in NZ, researchers elsewhere have emphasised the importance of the project delivery: Thomas et al. (2002: p. 79) describe the selection and use of an appropriate procurement system as 'crucial to project success'.

The effectiveness of procurement strategies has been linked to productivity (Building and Construction Productivity Partnership, 2010; Wilkinson and Scofield, 2010), innovation (de Valence, 2010; Loosemore, 2014) and the potential for conflict and 
disputes (Heaphy, 2011; Jelodar et al., 2016; Mosey, 2011). Internationally, there are growing trends towards more use of offsite manufacturing (OSM) to resolve many of these issues, including labour shortage and productivity. The NZ construction industry is no exception (PrefabNZ, 2015).

OSM is a form of modern method of construction (MMC) in which a key principle is to transfer work off-site, and includes systems such as modules, volumetric pods, panels and hybrid components (Wilkinson and Scofield, 2010).

Some of the benefits have been described by Wilkinson and Scofield (2010), including reduced on-site congestion, shortened project durations, reduced time-related costs allowing for earlier building close-in, reduced labour costs and improved quality through producing work in more controlled environments. However, there are numerous challenges associated with OSM. The design must be finalised earlier, making changes during the construction phase more difficult. In addition, tolerances can be difficult to maintain, resulting in connectivity issues; transported units are subject to size and weight restrictions; units require protection during delivery and storage; and an increased reliance is placed on manufacturers to deliver when promised. Tradespeople who are passionate about their craft may be reluctant to adopt OSM processes.

Despite drivers towards the MMC concept, its uptake is not without challenges. Shahzad (2011) classifies the main barriers to the adoption of OSM in NZ into seven broad categories (in descending order of impact and relative contributions): industry and market culture (16.2\%), skills and knowledge (15.5\%), logistics and site operations (14.8\%), cost/value/productivity (14\%), supply chain and procurement $(13 \cdot 7 \%)$, process and programme $(13 \cdot 6 \%)$ and regulatory issues $(12 \cdot 2 \%)$. Under the category of industry and market culture, a conservative market approach and client mindset was found to be a prominent constraint. The limited expertise of designers to handle OSM designs and the lack of experienced manufacturers were constraints under skills and knowledge. The lack of research and development into OSM was also noted. Design-related issues were the most prominent constraints under process and programme. The main issue is that OSM design choices must be made during design development, resulting in limited freedom to make design changes after the construction phase starts. Another issue relates to connectivity problems on-site and the potential 'mismatch between design and the manufacturing process' (Shahzad, 2011: p. 47). Issues associated with transporting large modular or pre-fabricated units and site restrictions affecting space required for craneage and manoeuvrability of heavy plant and equipment were the most significant constraints under logistics and site operations. This correlates with the main constraints under the cost/value/productivity category, which include concerns about increased project costs for transportation of OSM units, particularly modular or large units, and for the increased use of craneage.
Most of the constraints, including difficulties for designers to incorporate OSM technology, connectivity and potential mismatch between design and manufacturing and issues with transportation and site restrictions, may be summarised as design buildability issues. Some of these may also contribute to the first constraint conservative market culture - particularly given the need to finalise design decisions earlier and the consequent difficulty to make changes during construction. Because OSM integrates design and manufacturing, it is critical to involve key constructors in the design process. Indeed, the integration of construction knowledge to maximise project performance is at the heart of the definitions of 'constructability' (see CII (1998) and CIIA (1992)), which, according to Jergeas (2009), is used interchangeably with the term 'buildability'.

Under single-stage procurement, clients risk commissioning a design which, when tendered, is found to be unnecessarily difficult or even impossible to build. Involving the constructor in design development may reduce this risk. A standard model may help overcome the most prominent barrier to OSM adoption, industry and market culture $(16 \cdot 2 \%)$, which is a conservative market approach and client mindset, because standard forms of contract provide familiarity and can be tried and tested over time (Ashworth, 2012).

Through ECI, works can be collaboratively planned, harnessing the contractor's buildability knowledge to foresee risks and maximise value (Laryea and Watermeyer, 2016; Mosey, 2011; Pheng et al., 2015; Rahmani et al., 2014; Song et al., 2006; Whitehead, 2009). Specific information contributed by the contractor can include aspects such as resource availability and limitations in terms of cost, performance, access and site conditions (Song et al., 2009: p. 13). Benefits of such collaboration include reducing disputes (Mosey, 2011), more transparent pricing (Berends, 2006; Mosey, 2011; Whitehead, 2009), reduced design changes, avoidance of delays and achievement of pre-fabrication-to-erection schedules (Song et al., 2009; Whitehead, 2009).

Despite all this, the ECI approaches lack clear definition. Debate exists around the extent that ECI should be considered as purely a partnership concept. In the UK, ECI is typically considered a form of partnering (Rahman and Alhassan, 2012). Some propose that only a charter is required; however, Mosey (2011) argues that strategies should recognise the commercial interests of the contracting parties. Rahmani et al. (2013: p. 2) describe a twostage model where contractors are selected on a purely non-price basis to assist with project planning and develop an 'open-book' target cost. In contrast, Pheng et al. (2015) describe a two-stage approach that allows contractors' participation in the design process while maintaining competitive pricing. Contractors can be invited to tender a price based on a notional bill of quantities, and then once the design is finalised, a firm bill of quantities is developed by applying the rates from the original tender.

There is currently no standard model for two-stage ECI in NZ. ECI contracts have generally remained confined to large 
infrastructure projects in countries such as Australia, NZ, the UK, the Netherlands and the USA (Rahmani et al., 2013). In Australia, Whitehead (2009) describes hybrid models where the first stage is a form of partnering and the second stage is often a DB contract. Examples of those that have adopted this approach include South Australia's Department for Transport Energy and Infrastructure and Queensland's Department of Transport and Main Roads.

The Joint Contracts Tribunal (JCT) publishes the MC Management Building Contract 2011 (JTC, 2011) within its suite of contracts. However, this is a single contract, which covers both pre-construction and construction stages, rather than a two-stage process. It has also been criticised for its risk allocation approach and is reportedly the least-used contract in the JCT suite of contracts (see Glover (2013)). The NEC3 suite also includes a management contract option: Engineering and Construction Contract Option F: Management Contract. Unlike more traditional lump sum construction contracts, NEC (2014a) describes it as a 'cost reimbursable management contract where the financial risk is taken largely by the client'. In January 2016, NEC released a supplementary additional ECI clause for use with Engineering and Construction Contract options C (target contract with activity schedule) and $\mathrm{E}$ (cost reimbursable contract) (NEC, 2016). The ECI clause provides basic pre-construction provisions. However, the NEC's FAQs webpage (NEC, 2014b) clarifies that the ECI clause is not suitable for use with lump sum contracts. The JCT suite was updated in 2016, and NEC4 was released in 2017 (NEC, 2017). However, the contractual amendments do not fundamentally affect the approaches to the JCT MC and CM contracts or the NEC ECI clause.

In 2011, the JCT launched, as part of its suite, the Pre-construction Services Agreement (General Contractor) (PCSA) and Preconstruction Services Agreement (Specialist) (PCSA/SP). Like bespoke use in NZ, these act as a supplement to a standard form of construction contract - in this case, the JCT standard contracts for building works only or for DB. The latest version of JCT's PCSA, PCSA 2016 (JCT, 2016a) and PCSA/SP 2016 (JCT, 2016b), is described by the JCT as being designed for appointing a contractor to carry out pre-construction services under a two-stage tender process. The PCSA is claimed to enable the contractor to 'collaborate with the employer or their team of consultants to develop detailed designs, to develop the main contract works, or to compile specialist tender documents' (JCT, 2016a). It also claims that ECI enables the contractor to make preparation for the construction phase, such as the programme, cost plans, buildability and any specialist procurement.

These agreements provide a range of standard provisions and enable parties to set out the pre-construction services and methods of payment.

In NZ, an operation manager for a nationwide construction company estimates that $25-30 \%$ of their turnover in the Otago Region is through two-stage ECI (personal communication, 5 September 2016). In the second-stage construction contract, where the contractor may be responsible for either DB or construction only, the manager estimates that construction only is more common. This contrasts with Francis and Kiroff (2015), who researched perceptions of ECI in NZ and asserted that DB is the most common form of ECI in NZ commercial construction.

\subsection{Research strategy and what this adds to the body of knowledge}

Procurement systems that enable ECI are evaluated in terms of how well they support OSM. A conceptual process model for two-stage ECI is developed. Key variables are identified from literature; three ethnographic case studies in Dunedin, Otago, NZ, between 2006 and 2017; and document analysis. The construction costs of the three case study projects are in the approximate range NZ\$10-20 million (US\$6.84-13.7 million, $£ 5 \cdot 26-10 \cdot 52$ million). Two involved complex alterations and extensions with high levels of building services. The third is an accommodation building comprising pre-fabricated timber structure. The lead author worked as the head contractor's quantity surveyor in two projects between 2006 and 2009. The range of pre-construction services is identified through open coding from ECI-related literature. Legal doctrine is used to distinguish between obligations for design buildability against design compliance with codes and standards. Each variable is considered in terms of optimal process based on theory and clarity of risk allocation. The conceptual model was presented at a conference, and two further pre-construction services were added following feedback. Features of the model are aligned with overcoming the barriers to OSM adoption.

\section{Procurement needs for OSM}

It is generally agreed that there is no one perfect procurement strategy; rather, a strategy should be based on sensible policy (Murdoch and Hughes, 2008) and aligned with the client's requirements and the nature of their project (Kirkham, 2007). Decision-making criteria include

n involvement of the client with the construction process

- separation of design from management

- reserving the client's right to alter the specification

- clarity of client's contractual remedies

- complexity of the project

- speed from inception to completion

- certainty of price.

A range of procurement pathways exists for any construction project. Given the lack of clear definitions, Rowlinson and McDermott (1999) describe the debate on whether the term 'system' or 'model' is appropriate to describe the options. Nevertheless, the following procurement 'models' are generally recognised: DB, traditional (general contracting), $\mathrm{CM}$ and $\mathrm{MC}$. In $\mathrm{DB}$, the contractor has single-point responsibility for both design and construction; in traditional contracting, the client employs a design team to produce the design which when complete is tendered to builders; in MC, the head contractor subcontracts all trade packages, allowing them to be involved during the design 
stage more like a consultant; and in $\mathrm{CM}$, the client employs all the trade contractors directly and a consultant to manage them.

For clients and consultants to make informed design decisions on projects involving OSM, Elnaas et al. (2009) recommend that procurement practices should facilitate the sharing of cost and buildability knowledge among manufacturers, constructors and designers. Single-stage procurement fails to resolve the buildability constraints of OSM because the contractor does not see the design until it is already fully developed. Kirkham (2007) demonstrates clearly how the potential for added value diminishes and the cost of change increases as the design is developed.

The most prominent barrier to the uptake of OSM was the reluctance to adopt unfamiliar processes. Jergeas and Put (2001) found the risk aversion of owners and lack of knowledge of latest construction methods to be key barriers to innovation. A key advantage of traditional lump sum contracts is that the procedures are well understood and the standard forms of construction contract provide familiarity and reliability through being well tried in case law (Ashworth, 2012; Kirkham, 2007). Traditional lump sum contracts remain the dominant contract form, accounting for about $75 \%$ of construction projects by number in the UK, with DB the second most used at around $17 \cdot 5 \%$ (RICS, 2010).

Therefore, the optimal procurement strategy to enhance OSM should enable contractor involvement in the design, effectively allocate the risks of design and buildability, enable competitive lump sum pricing and be developed in the form of a standard model than can become familiar and tested over time. Procurement models that provide ECI include DB, MC, CM, partnering and alliance contracts and general contracting with two-stage tenders.

\section{Procurement systems suitable for OSM}

DB procurement would be suitable for projects with OSM where the design is straightforward and changes during construction are unlikely. Under CM and MC, the consultant or head contractor can provide input to the design around planning and buildability, while the client retains ownership of the design. The project can be fast-tracked by overlapping design and construction, and OSM elements can be ordered in time to avoid delay. If pricing is equal, the reduced risk exposure of MC is advantageous over CM for lay clients. Under CM, the client employs the specialist contractors directly with a consultant to manage them and so adopts more risk than the single-point accountability of a head contractor.

Consultant construction managers do incur implied legal obligations, including warning the client of poor performance by others in the project team (Chesham Properties Ltd v. Bucknall Austin Management Services [1996]); coordinating trade works (Donohoe and Brooks, 2007); planning, monitoring and controlling activities and resources (Griffith and Watson, 2004); and warning the client of contractual risk (Monastiriotis and Bodnar, 2013; Plymouth \& South West Co-Op Soc. Ltd v.
Architecture, Structure \& Management Ltd [2006]). However, their duty is limited to taking reasonable skill and care, whereas a head contractor's liability is absolute or a fitness-for-purpose obligation. For example, contractors are responsible for any building defects and may be liable for liquidated or general damages. In contrast, if a project is delivered late under CM, the client must rely on the consultant having sufficiently accurate records to pinpoint the damages on individual trade contractors, or the client must prove that the breach is a consequence of the consultant's negligence (Monastiriotis and Bodnar, 2013). Moreover, Laryea (2010) found that contractors' buildability and pricing advice may be more accurate than that of consultants', on the basis that contractors perform the works and are contractually accountable for the accuracy of their estimates. This could be beneficial when comparing costs between OSM and traditional assemblies. A two-stage procurement process may be used to select a contractor for $\mathrm{DB}$, construction only or management only.

\section{Findings: key variables of pre- construction stage}

From the case studies, key variables in first stage of the two-stage process include

- the scope of services to be provided by the contractor, such as planning and sequencing the works, designing elements, providing buildability advice, risk management, value management and procuring subcontractors

v how or whether the contractor is reimbursed for their early input, such as no payment, lump sum component of preliminaries and cost reimbursement

- the grounds under which the project may be terminated without proceeding to the construction phase, such as going over budget and external intervener groups

- what happens if the project does not proceed to the construction phase, such as the contractor not charging for their early involvement, the contractor not charging but is paid if the project does not proceed to construction or the contractor does charge but offers a discount if the project does proceed to construction

- whether the contractor is to perform any direct works (such as the head contractor performing concrete and carpentry works) and if so, how this is priced, such as competitive lump sum or whether any fixed rates are to be provided against provisional quantities to be remeasured against the detailed design later

- the clear allocation of design and buildability obligations

- who owns any intellectual property

- key milestones for providing information

- contractual provisions that encourage a collaborative culture, such as requiring parties to act in 'good faith', or 'mutual trust and co-operation'.

The preceding model was presented at the Modular Construction and Pre-fabrication Conference in Auckland, NZ, in December 2017. The following pre-construction services were suggested during the feedback session 
- liaising with local authorities to obtain compliance for prefabricated components

- coordinating documentation for building information modelling (BIM).

The following sections expand on some of the variables and consider alternative options in terms of theory and risk allocation.

\subsection{Pricing and timing}

Head contractors were found to tender first-stage prices generally based on the following

a lump sum price for the preliminary and general (P\&G) works for the whole project, including where construction work is staged.

- a lump sum price for the construction of any first stage for which design is already developed (for example, where the project is released in stages)

nercentages to be applied for on-site and off-site overheads and profit to be applied to variations and subcontractors to be procured

- fixed rates for provisional quantities of any direct construction works (for example, carpentry and concrete) based on conceptual design

non-price attributes such as a base construction programme, methodology and history of similar past projects.

Lump sum contracts provide price surety before work starts. Risks are transferred to the contractor with narrow grounds under which the contractor can claim additional costs or time. In a cost reimbursement contract, the contractor is paid based on agreed rates and percentages applied to materials and subcontractors. However, this may incentivise the contractor to overspend (Turner, 2004). A target value or guaranteed maximum price may be used with gain-share/pain-share provisions to align goals. However, auditing is required to ensure claims are accurate.

One argument for partnering with open-book pricing is that the lack of defined scope at the time of early involvement prohibits competitive pricing (Rahman and Alhassan, 2012: p. 218). However, lump sum pricing can be determined for preliminary works so long as sufficient concept design exists to establish such requirements such as management, supervision, insurances and temporary works. Head contractors can declare margins for profit and overheads to apply to subcontractors and variations, plus a lump sum construction price for any first-stage work already designed or fixed rates for carpentry and concrete works against a provisional schedule of quantities. The quantities can then be remeasured once the design is developed to produce a bill of quantities applying the rates of the original tender (see Pheng et al. (2015)) and arrive at a lump sum construction price. Because the quantities are only provisional and will be remeasured, they could be measured by a consultant quantity surveyor or the contractor. The client or consultant will need to check the accuracy of the contractor's final quantities.
The timing of contractor involvement is crucial to enabling competitive and accurate pricing. Some argue that to maximise value, contractors should be involved from 'day one' of the design process (Jergeas and Put, 2001: p. 283). Others contend that a concept design is needed first because if the client has very specific ideas about the finished product, the contractor may have nothing to add or may waste time developing proposals for a client who does not know what they want (Francis and Kiroff, 2015). If the contractor is appointed too early, they might lack motivation to appoint their best staff and there can be a loss of design creativity if the team does not work well together and the designer steps back as the contractor pursues buildability and cost-saving efficiencies (Whitehead, 2009). In addition, it is arguable that, generally, designers prefer to work solely with their client to develop concept design (Francis and Kiroff, 2015). On the whole, it is contended that the optimum time for contractor engagement is once a sufficient conceptual design exists to enable competitive lump sum pricing for preliminaries and fixed rates against provisional quantities for direct works. Delaying beyond this will reduce the contractor's potential to evaluate design options.

\subsection{Payment}

One drawback of two-stage ECI is that the client pays for the contractor earlier than they would under single-stage tenders and may pay for the contractor's cost of pricing construction. However, when contractors tender in the open market, they incur the cost of tendering with a higher risk of not winning. Pricing the first-stage of ECI incurs fewer resources than preparing a full tender, and then if successful, the contractor works towards a well-planned project that they can be reasonably sure of proceeding. Therefore, why should the client pay for the contractor to price construction work under ECI? Figure 1 demonstrates the two-stage conceptual process model based on no payment for the pre-construction stage unless the project does not proceed to construction.

Laryea and Watermeyer (2016: p. 4) provide case studies of two construction projects for Wits University in South Africa procured through two-stage ECI in which the contractor received 'no remuneration for the involvement in design development' as 'they value the benefits of developing early cost models and production plans.' In one of the case studies, the lead author worked as a contractor's quantity surveyor on an NZ\$9 million ( $£ 4.73$ million) health project in 2006-2008 procured through two-stage ECI where the contractor did not charge for their early involvement. The head contractor appointed in another of the case studies - a student accommodation project - is charging for their early involvement, but with a discount if the project proceeds to construction. Three options exist for first-stage pricing.

- The contractor does not charge for their involvement.

- The contractor does not charge, but is reimbursed if the client does not progress the project to construction phase.

- The contractor charges, but offers a discount if the project proceeds to construction phase. 


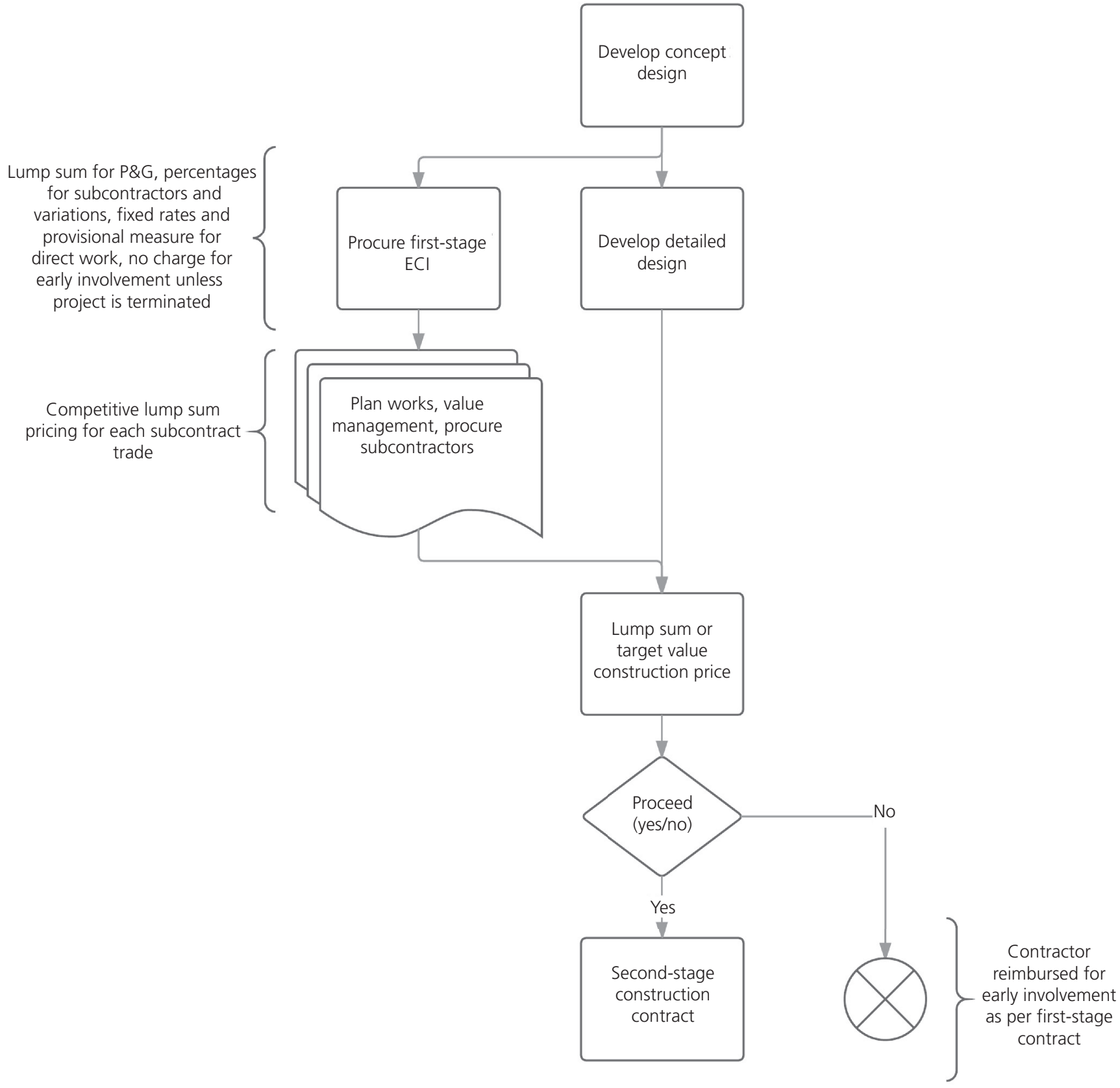

Figure 1. Two-stage ECl process model with no payment option for pre-construction stage. P\&G, preliminary and general works

Any first-stage price may be cost reimbursement or fixed price component of the lump sum preliminaries price.

\subsection{Pre-construction services}

Pre-construction services include the planning, design and procurement activities that lead up to the physical construction work. These may include planning and sequencing construction activities, design review and specialist design contributions, risk and value management and subcontractor procurement. According to Mosey (2011), early-stage contracts can support the project by setting out the head contractor's and subcontractors' contributions to buildability, affordability and design appropriateness, testing the scope for savings and evaluating the viability of new ideas across the project's whole life cycle. Mosey (2011) recommends that a communication plan be included and a programme that includes deadlines for team members to provide information. This is echoed by the Centre of Construction Law and Dispute Resolution (2016), which recommends that any procurement processes to support BIM should set out key milestones for providing information, address who owns intellectual property and provide contractual provisions that encourage collaboration. Pre-construction services have been open-coded from literature and are presented in Table 1. 
Table 1. Pre-construction services open-coded from literature

\begin{tabular}{|c|c|}
\hline Pre-construction services & Sources \\
\hline \multicolumn{2}{|r|}{ Design management } \\
\hline Planning and coordination of design & Tzortzopoulos and Cooper (2007), Sidwell (1983) \\
\hline $\begin{array}{l}\text { Stakeholder management and } \\
\text { communication strategy }\end{array}$ & $\begin{array}{l}\text { Tzortzopoulos and Cooper (2007), Mosey (2011), New Zealand Ministry of Education (2017), } \\
\text { Berends (2006) }\end{array}$ \\
\hline Development of design brief & Tzortzopoulos and Cooper (2007), New Zealand Ministry of Education (2017) \\
\hline \multicolumn{2}{|r|}{ Construction planning } \\
\hline $\begin{array}{l}\text { Planning and sequencing } \\
\text { construction activities }\end{array}$ & El-sayegh (2009), Mosey (2011), Kashiwagi et al. (2009), Sidwell (1983) \\
\hline Buildability evaluation & $\begin{array}{l}\text { Laryea and Watermeyer (2016), Pheng et al. (2015), Rahman and Alhassan (2012), Mosey (2011), } \\
\text { Rahmani et al. (2014), Whitehead (2009), Song et al. (2006), Jergeas and Put (2001), Sidwell (1983) }\end{array}$ \\
\hline \multicolumn{2}{|r|}{ Financial services } \\
\hline Budget advice & Kirkham (2007), Laryea (2010), Sidwell (1983) \\
\hline Value management & Mosey (2011), Kirkham (2007), Whitehead (2009), Jergeas and Put (2001), Kashiwagi et al. (2009) \\
\hline Risk management & $\begin{array}{l}\text { Rahman and Alhassan (2012), Mosey (2011), New Zealand Ministry of Education (2017), Jergeas and } \\
\text { Put (2001), Kashiwagi et al. (2009) }\end{array}$ \\
\hline & Supply chain \\
\hline $\begin{array}{l}\text { Subcontractor and supplier } \\
\text { procurement }\end{array}$ & El-sayegh (2009), Whitehead (2009), Mosey (2011), Sidwell (1983) \\
\hline
\end{tabular}

If the head contractor becomes involved once the concept design is developed, stakeholder management and development of the design brief must be done by the client's project manager or architect. The remainder could be specified for the contractor.

\subsection{Obligations for design and buildability}

A risk of adopting OSM technology involves unknown buildability issues rendering the design more expensive to construct than comparable traditional assemblies or, worse, tendering a fully developed design only to find that the design is not buildable.

The implied legal duty imposed on a designer or project manager is that of reasonable skill and care. The test is measured against what any other ordinarily skilled person in the same discipline would have done given similar circumstances (Bolam v. Friern Hospital Management Committee [1957]; Powell, 2009; Read, 2004).

The implied legal duty imposed for construction work is fitness for purpose. Fitness for purpose imposes a higher standard than that of reasonable skill and care. The standard is absolute guarantee of product performance imposed on manufacturers, which also falls onto contractors in the construction sector (Burrows et al., 2012). Where a contractor is also responsible for design, their implied legal duty defaults to fitness for purpose (Brown, 2011; Steensma, 2010). Therefore, where a manufacturer designs and supplies prefabricated modular or pre-fabricated elements, they are responsible for those elements being fit for their intended purpose and defect free, regardless of what any other designer would have done, unless the contract provides otherwise. Like most published standard forms of construction contracts around in the UK and many other Commonwealth jurisdictions, published construction contracts in NZ such as the NZS 3910:2013 (clause 5.1.4) (Standards New Zealand., 2013), NZIA SCC 2014 (clause 8.6.5) (New Zealand
Institute of Architects, 2014) and the Registered Master Builders Federation of New Zealand's SA-2009 (clause 6.1.1) (RMBF, 2009) all reduce the liability for any contractor's design work to that of reasonable skill, care and diligence.

Designers are responsible for ensuring that their design will perform according to relevant codes when constructed using reasonable standards of workmanship (George Fischer Holding Ltd v. Multi Design Consultants Ltd (1998)) and levels of supervision (Equitable Debenture Assets Corporation Ltd v. William Moss Group Ltd (1984)). This is reflected in New Zealand's Building Act 2004 (New Zealand Government, 2017), which requires designers to produce designs in compliance with the New Zealand Building Code (Building Performance, 2017) when built using reasonable standards of workmanship.

By offering a lump sum price, a contractor warrants that $(a)$ they can build what has been designed and $(b)$ they can build it for the price offered. Anything that makes the work more difficult is the contractor's risk, including design defects from a buildability perspective (Rosenberg, 2012). Once appointed, contractors are legally required to notify the designer of certain design defects (Glover, 2006).

Standard forms of construction contracts commonly relieve the contractor for reasonably unforeseeable physical conditions that substantially affect the cost of the work. This would cover instances where the contractor uncovers unexpected rock during excavation work or unexpected steel structure or asbestos when wall linings are removed. However, such provisions would unlikely cover redesigns required in the event of site restrictions making delivery of pre-cast panels undeliverable, or where pre-fabricated components are designed too large for manufacturing facilities, or where designed 
windows do not fit prepared openings due to connectivity issues with the design. The first-stage pre-construction contract provides an opportunity to address these risks.

\section{Conclusions}

ECI offers significant advantages for projects that use OSM technologies. Designers and contractors can work collaboratively in developing the design, managing risks, undertaking value management exercises and procuring specialist subcontractors. The contractor can evaluate the costs and buildability of design options - for example, by comparing OSM technology with more traditional assemblies - and adopt clearer contractual responsibility for design buildability than is afforded under many standard forms of construction contracts. The more integrated approach overcomes the current segmentation and enables the client and designers to make more informed decisions about adopting OSM and can reduce the potential for future buildability problems and related variations and disputes during construction. Depending on whether or how the contractor is paid for their early involvement, there may be little or no additional cost to the client - recognising the benefit to the contractor of a better planned and more buildable project.

Contract documentation for the first stage of two-stage ECI should clearly set out among other things $(a)$ the scope of services to be provided by the contractor such as planning, budgeting, buildability evaluation, risk management, value management and subcontractor procurement; $(b)$ key milestones for communication exchange and supply of elements; (c) who owns intellectual property; $(d)$ whether or how the contractor is paid for their early involvement; $(e)$ under what grounds the client can terminate the project; $(f)$ what happens if the project does not proceed to the construction phase; and $(g)$ parties' obligations around design and construction, whether for individual elements or for the overall design, and the contractor's early notification of design issues.

Opportunity exists in NZ to develop a standard form of first-stage pre-construction contract for two-stage ECI procurement for use with a standard form of construction contract for the second stage (such as NZS 3910:2013 or NZIA SCC 2014). This could help overcome the barrier to OSM relating to the conservative market culture by becoming familiar and tested over time. Provision for competitive lump sum pricing across all tiers of the supply chain may also suit risk-averse clients. To the extent that a standard model for two-stage ECI becomes recognised for reducing design buildability risk, it is conceivable that in extreme cases, consultants could potentially be held negligent for not recommending ECI processes for complex projects and exposing their client to unjustifiable design buildability risks.

\section{REFERENCES}

Ashworth A (2012) Contractual Procedures in the Construction Industry, 6th edn. Pearson Essex, UK

Australia and New Zealand Governments (2013) Australia and New Zealand Government Procurement Agreement. See http://www. procurement.govt.nz/procurement/for-suppliers/working-with-government/ australia-new-zealand-government-procurement-agreement-1.47-mb-pdf/ view (accessed 20/12/2017).

Berends TC (2006) Cooperative contracting on major engineering and construction projects. The Engineering Economist 51(1): 35-51, https://doi.org/10.1080/00137910500524844.

Bolam v. Friern Hospital Management Committee [1957] 1 WLR 582.

Brown J (2011) Do Design and Build Insurance Policy Wordings Fit the Bill? Society of Construction Law. Hinckley, UK. D120.

Building Construction Productivity Partnership (2010) Productivity Roadmap. Building and Construction Sector Productivity Partnership, Wellington, New Zealand. See http://www.parliament.nz/resource/ 0000182839 (accessed 10/11/2017).

Building Performance (2017) Building Code Compliance. Ministry of Business, Innovation \& Employment, Wellington, New Zealand. See https://www.building.govt.nz/building-code-compliance/ (accessed 20/12/2017)

Burrows J, Finn J and Todd S (2012) Law of Contract in New Zealand, 4th edn. Lexis Nexis Wellington, New Zealand.

Centre of Construction Law Dispute Resolution (2016) Enabling BIM through Procurement and Contracts. Centre of Construction Law and Dispute Resolution, King's College London, London, UK. See https:// www.kcl.ac.uk/law/research/centres/construction/enabling-bim/ ebimtpac-form.aspx (accessed 10/11/2017).

Chesham Properties Ltd v. Bucknall Austin Management Services [1996] 82 BLR 92.

CII (Construction Industry Institute) (1998) Reforming Owner, Contractor, Supplier Relationships: a Project Delivery System to Optimize Supplier Roles in EPC Projects. CII, Austin, TX, USA. RS130-1. See https://www.construction-institute.org/resources/knowledgebase/ knowledge-areas/general-cii-information/topics/rt-130/pubs/rs130-1 (accessed 10/11/2017).

CIIA (Construction Industry Institute Australia) (1992) Constructability Principles File. CIIA, Brisbane, Australia.

de Valence G (2010) Innovation, procurement and construction industry development. Australasian Journal of Construction Economics and Building 10(4): 50-59, https://doi.org/10.5130/AJCEB.v10i4.1883.

Donohoe S and Brooks L (2007) Reflections on construction management procurement following Great Eastern Hotel Company v. John Laing. Construction Management and Economics 25(7): 701-708, https://doi org/10.1080/01446190601139909.

Elnaas H, Ashton P and Gidado K (2009) Decision making process for using off-site manufacturing (OSM) systems for housing projects. In Proceedings 25th Annual ARCOM Conference (Dainty A (ed.)). Association of Researchers in Construction Management, Cambridge, UK, pp. 887-895. See http://www.arcom.ac.uk/-docs/proceedings/ar2009-08870895 Elnaas Ashton and Gidado.pdf (accessed 10/11/2017).

El-sayegh S (2009) Multi-criteria decision support model for selecting the appropriate construction management at risk firm. Construction Management and Economics 27(4): 385-398, https://doi.org/10.1080/ 01446190902759009.

Equitable Debenture Assets Corporation Ltd v. William Moss Group Ltd (1984) 2 Con LR 1, TCC (also reported in 1 Const LJ 131).

Francis S and Kiroff L (2015) Attitudes and perceptions towards early contractor involvement procurement. In Proceedings of the RICS COBRA AUBEA 2015 Conference. Royal Institution of Chartered Surveyors, London, UK. See http://unitec.researchbank.ac.nz/bitstream/ handle $/ 10652 / 3179 /$ Attitudes $\% 20$ and $\% 20$ Perceptions $\% 20$.pdf? sequence $=$ $1 \&$ isAllowed=y (accessed 28/06/2016).

George Fischer Holding Ltd v. Multi Design Consultants Ltd (1998) 61 Con LR 85.

Glover J (2006) Liability for Defects in Construction Contracts - Who Pays and How Much? Fenwick Elliot, London, UK. See http://www fenwickelliott.com/files/Contract $\% 2010 \% 20-\% 20$ Liability $\% 20$ for $\%$ 20Defects.pdf (accessed 10/11/2017). 
Glover J (2013) Management Contracting - the JCT Management Contract: a Review. Fenwick Elliot, London, UK. See https://www. fenwickelliott.com/research-insight/annual-review/2013/managementcontracting-jct-review (accessed 20/12/2017).

Griffith A and Watson P (2004) Construction Management: Principles and Practice. Palgrave MacMillan, Basingstoke, UK.

Heaphy I (2011) Do Target Cost Contracts Deliver Value for Money? Society of Construction Law, Hinckley, UK.

ICE (Institution of Civil Engineers) (2016) Civil Engineering Procedure, 7 th edn. ICE Publishing, London, UK.

JCT (The Joint Contracts Tribunal) (2011) MC 2011 Management Building Contract 2011. JCT, London, UK. See https://www.jctltd.co.uk/ product/management-building-contract (accessed 20/12/2017).

JCT (2016a) Pre-Construction Services Agreement (General Contractor) (PCSA) 2016. JCT, London, UK. See https://www.jctltd.co.uk/product/ pre-construction-services-agreement-general-contractor (accessed 20/12/2017).

JCT (2016b) Pre-construction Services Agreement (Specialist) (PCSA/SP) 2016. JCT, London, UK. See https:/www.jctltd.co.uk/product/preconstruction-services-agreement-specialist (accessed 20/12/2017).

Jelodar M, Yiu T and Wilkinson S (2016) Relationship-quality judgment model for construction project procurement: a conjoint measurement. Journal of Construction Engineering and Management 142(7): 89-103, https://doi.org/10.1061/(ASCE)CO.1943-7862.0001104.

Jergeas G (2009) Improving Construction Productivity on Alberta Oil and Gas Capital Projects. Alberta Finance and Enterprise, University of Calgary, Calgary, AB, Canada. See http:/www.albertacanada.com/ files/albertacanada/improving_construction_productivity.pdf (accessed 10/11/2017)

Jergeas J and Put J (2001) Benefits of constructability on construction projects. Journal of Construction Engineering and Management 127(4) 281-290, https://doi.org/10.1061/(ASCE)0733-9364(2001)127:4(281).

Jorgensen B and Emmitt S (2007) Integrating design and construction from a 'lean perspective'. In 17th CIB World Building Congress: Construction for Development, Cape Town, South Africa. CIB, Rotterdam, the Netherlands, pp. 1080-1092, CIB2007-2.

Kashiwagi D, Kashiwagi J and Savicky J (2009) Industry structure: misunderstood by industry and researchers. NED University Journal of Research 6(2): 59-76.

Kirkham R (2007) Ferry and Brandon's Cost Planning of Buildings, 8 th edn. Blackwell Singapore, Singapore.

Laryea S (2010) Contractor project estimates vs. consultant project estimates in Ghana. The Construction, Building and Real Estate Research Conference of the Royal Institute of Chartered Surveyors. Paris, France. See http://centaur.reading.ac.uk/16290/1/ Contractor_project_estimates_versus_consultant_project_estimates in Ghana.pdf (accessed 10/11/2017).

Laryea S and Watermeyer R (2016) Early contractor involvement in framework contracts. Proceedings of the Institution of Civil Engineers - Management, Procurement and Law 169(1): 4-16, https://doi.org/10. 1680/jmapl.15.00012

Loosemore M (2014) Improving construction productivity: a subcontractor's perspective. Engineering, Construction and Architectural Management 21(3): 245-260, https://doi.org/10.1108/ ECAM-05-2013-0043.

MBIE (Ministry of Business Innovation Employment) (2013) New Zealand Construction Sector Report. MBIE, Wellington, New Zealand. See http://nzcic.co.nz/wp-content/uploads/2015/10/MBIE-ConstructionSector-Report-2013.pdf (accessed 10/11/2017).

Monastiriotis E and Bodnar A (2013) Construction Professional Negligence Update. Society of Construction Law, Hinckley, UK. D159.

Mosey D (2011) The Strengths of Early Contractor Procurement. Society of Construction Law, London, UK, paper 171.

Murdoch J and Hughes W (2008) Construction Contracts: Law and Management, 4th edn. Taylor \& Francis New York, NY, USA.
NEC (2014a) NEC3: Engineering and Construction Contract Option F: Management Contract. NEC, London, UK. See https://www. neccontract.com/NEC3-Products/NEC3-Contracts/NEC3-EngineeringConstruction-Contract/NEC3-Engineering-and-Construction-ContractECC-/NEC3-Engineering-and-Construction-Contract-Option-4 (accessed 17/05/2017).

NEC (2014b) FAQs. NEC, London, UK. See https://www.neccontract.com/ NEC-in-Action/FAQs/Best-use-of-ECI-clauses (accessed 17/05/2017). NEC (2016) NEC3: Early Contractor Involvement. NEC, London, UK. See https://www.neccontract.com/getmedia/9c65871f-bfae-405e-976913f7627014c5/NEC_ECI_Jan2016-Web.pdf.aspx (accessed 17/05/2017).

NEC (2017) NEC4: Contracts. NEC, London, UK. See https://www. neccontract.com/NEC4-Products/NEC4-Contracts (accessed 20/12/2017).

New Zealand Institute of Architects (2014) Standard Conditions of Contract. New Zealand Institute of Architects, Auckland, New Zealand, NZIA SCC 2014. See https://www.nzia.co.nz/e-shop.aspx (accessed 17/05/2017)

New Zealand Government (2017) Building Act 2004. Public Act 2004 No. 72. Parliamentary Counsel Office, Wellington, New Zealand. See http://legislation.govt.nz/act/public/2004/0072/latest/DLM306036.html (accessed 15/05/2017).

New Zealand Ministry of Education (2017) Role of a Project Manager. New Zealand Ministry of Education, Wellington, New Zealand. See http://www.education.govt.nz/school/property/state-schools/projectmanagement/role-of-a-project-manager/ (accessed 10/11/2017).

Pheng L, Gao S and Lin J (2015) Converging early contractor involvement (ECI) and lean construction practices for productivity enhancement some preliminary findings from Singapore. International Journal of Productivity and Performance 64(6): 931-852, https://doi.org/10.1108/ IJPPM-02-2014-0018.

Plymouth \& South West Co-Op Soc. Ltd v. Architecture, Structure \& Management Ltd [2006] ABC LR 01/10. See http://www.nadr.co.uk/ articles/published/ConstructionLawReport/Plymouth $\% 20 \mathrm{v} \%$ 20Architecture\%202006.pdf (accessed 13/06/2017).

Powell J (2009) Professional Liability and Construction: Risk Retained and Risk Transferred. Society of Construction Law, Hinckley, UK, D160.

PrefabNZ (2015) Levers for Prefab. PrefabNZ, Wellington, New Zealand, http://www.prefabnz.com/resources (accessed 13/06/2017).

Rahman M and Alhassan A (2012) A contractor's perception on early contractor involvement. Built Environment and Asset Management 2(2): 217-233, https://doi.org/10.1108/20441241211280855.

Rahmani F, Khalfan M and Maqsood T (2013) The use of early contractor involvement in different countries. In Proceedings of the 38th AUBEA Conference, Auckland, New Zealand, 20-22 November 2013 (Yiu TW and Gonzalez V (eds)). The University of Auckland, Auckland, New Zealand, pp. 1-10.

Rahmani F, Khalfan M and Maqsood T (2014) The application of early contractor involvement (ECI) in different delivery systems in Australia. In Proceedings of CIB 2014 International Conference on Construction in a Changing World, Heritance Kandalama, Sri Lanka. University of Salford, Salford, UK, pp. 1-12. See https://researchbank. rmit.edu.au/view/rmit:25892 (accessed 10/11/2017).

RMBF (Registered Master Builders Federation of New Zealand) (2009) Subcontract Agreement SA-2009. RMBF/New Zealand Specialist Trade Contractors Federation Inc, Wellington, New Zealand.

Read G (2004) Professional Negligence. Nationwide Academy for Dispute Resolution (UK) Ltd, Mid Glamorgan, UK. See http:// www.nadr.co.uk/articles/published/construction/ProfessionalNegligence.pdf (accessed 10/11/2017).

RICS (Royal Institution of Chartered Surveyors) (2010) Contracts in Use a Survey of Building Contracts in Use during 2010. RICS, London, UK. See http://www.rics.org/Global/CONTRACTS\%20IN\%20USE_FINAL_\% 20Nov2012_\%201teage_081112.pdf (accessed 10/11/2017).

Rosenberg K (2012) Design Risk Allocation under a Traditional Build Contract. Society of Construction Law, Hinckley, UK, D140. 
Management, Procurement and Law

Volume 171 Issue MP4
Enhancing off-site manufacturing

through early contractor involvement

$(\mathrm{ECI})$ in New Zealand

Finnie, Ali and Park
Rowlinson S and McDermott P (1999) Procurement Systems A Guide to Best Practice in Construction. E \& FN Spon, London, UK.

Shahzad W (2011) Off-site Manufacturing as a Means of Improving Productivity in New Zealand Construction Industry: Key Barriers to Adoption and Improvement Measures. Masters thesis, Massey University, Auckland, New Zealand. See http://mro.massey.ac.nz/ xmlui/handle/10179/2685 (accessed 10/11/2017).

Sidwell A (1983) An evaluation of management contracting. Construction Management and Economics 1(1): 47-55, https://doi.org/10.1080/ 01446198300000005 .

Song L, Mohamed Y and AbouRizk S (2006) Evaluating contractor's early involvement in design. In 2006 AACE International Transactions. AACE International, Morgantown, WV, USA.

Song L, Mohamed Y and AbouRizk S (2009) Early contractor involvement in design and its impact on construction schedule performance. Journal of Management in Engineering 25(1): 12-20, https://doi.org/ 10.1061/(ASCE)0742-597X(2009)25:1(12).

Standards New Zealand (2013) NZS 3910:2013: Conditions of contract for building and civil engineering construction. Standards New Zealand, Wellington, New Zealand.
Steensma A (2010) Implied Obligations of Non-hindrance and Cooperation in Construction Contracts. Society of Construction Law, Hinckley, UK, D120.

Thomas S, Luu D and Chen S (2002) Decision criteria and their subjectivity in construction procurement selection. Australasian Journal of Construction Economics and Building 2(1): 70-80, https:// doi.org/10.5130/AJCEB.v2i1.2888.

Toolanen B (2008) Lean Contracting Relational Contracting Influenced by Lean Thinking. $\mathrm{PhD}$ thesis, Luleå University of Technology, Luleå, Sweden.

Turner R (2004) Farsighted project contract management: incomplete in its entirety. Construction Management and Economics 2(1): 75-83, https://doi.org/10.1080/0144619042000186077.

Tzortzopoulos P and Cooper R (2007) Design management from a contractor's perspective: the need for clarity. Architectural Engineering and Design Management 3(1): 17-28.

Whitehead J (2009) Early contractor involvement - the Australian experience. Construction Law International 4(1): 20-26.

Wilkinson S and Scofield R (2010) Management in the New Zealand Construction Industry. Pearson, Auckland, New Zealand.

\section{How can you contribute?}

To discuss this paper, please email up to 500 words to the editor at journals@ice.org.uk. Your contribution will be forwarded to the author(s) for a reply and, if considered appropriate by the editorial board, it will be published as discussion in a future issue of the journal.

Proceedings journals rely entirely on contributions from the civil engineering profession (and allied disciplines). Information about how to submit your paper online is available at www.icevirtuallibrary.com/page/authors, where you will also find detailed author guidelines. 